\title{
Remote Sensing of Ecosystem Water Use Efficiency in Different Ecozones of the North China Plain
}

\author{
Yungang $\mathrm{Hu}^{1}{ }^{1}$, Guangchao $\mathrm{Li}^{2}$ and Wei Chen ${ }^{2, * \mathbb{C}}$ \\ 1 Beijing Key Laboratory for Architectural Heritage Fine Reconstruction \& Health Monitoring, School of \\ Geomatics and Urban Spatial Information, Beijing University of Civil Engineering and Architecture, \\ Beijing 100044, China; huyungang@bucea.edu.cn \\ 2 College of Geoscience and Surveying Engineering, China University of Mining \& Technology, \\ Beijing 100083, China; lgc911201@163.com \\ * Correspondence: chenw@cumtb.edu.cn
}

Citation: Hu, Y.; Li, G.; Chen, W. Remote Sensing of Ecosystem Water Use Efficiency in Different Ecozones of the North China Plain. Sustainability 2022, 14, 2526. https:// doi.org/10.3390/su14052526

Academic Editor: Hone-Jay Chu

Received: 16 December 2021

Accepted: 17 February 2022

Published: 22 February 2022

Publisher's Note: MDPI stays neutral with regard to jurisdictional claims in published maps and institutional affiliations.

Copyright: (C) 2022 by the authors. Licensee MDPI, Basel, Switzerland. This article is an open access article distributed under the terms and conditions of the Creative Commons Attribution (CC BY) license (https:// creativecommons.org/licenses/by/ $4.0 /)$.

\begin{abstract}
Water use efficiency (WUE), as an environmental factor of metabolism in different ecosystem functional areas, is a key indicator of the ecosystem carbon-water cycle. WUE is defined as the ratio of carbon absorbed by ecosystems to water evaporated. Exploring the spatiotemporal variation in carbon and water cycles in different ecological zones of the North China Plain and their driving factors is important for the ecological management and sustainable development of the different ecological zones in the North China Plain. Based on remote sensing data products, this paper studies the spatiotemporal variations of WUE and their driving factors in different ecological functional areas of the North China Plain from 2001 to 2017. This study found that: (1) The spatial distribution of WUE and gross primary production (GPP) in the North China Plain is similar, with the multiyear average of WUE at $0.74 \mathrm{~g} \mathrm{C} \mathrm{m}^{-2} \mathrm{y}^{-1}$. The variation trend of WUE is mainly affected by the variation trend of GPP (44.38\% of the area of the North China Plain). (2) The change trend of WUE mainly showed a mild decrease and a mild increase, accounting for $73.22 \%$ of the area of the North China Plain; the area with medium-low fluctuation of WUE accounted for the largest proportion, accounting for $59.90 \%$ of the area of the North China Plain. In addition, the multiyear average values of WUE in the ecological functional area are Qin Ling Mountains deciduous forests > Central China loess plateau mixed forests $>$ Mongolian-Manchurian grassland $>$ Ordos Plateau steppe $>$ Changjiang Plain evergreen forests $>$ Huang He Plain mixed forests $>$ Bohai Sea saline meadow, in the order from high to low. (3) The influence of precipitation on WUE was higher than that of temperature. The area of WUE that increased with the increase of precipitation accounted for $23.74 \%$ of the area of the North China Plain and was mainly distributed in the Qin Ling Mountains deciduous forests, Changjiang Plain evergreen forests, and Huang He Plain mixed forests' ecological functional areas. The results of the study can provide a reference and theoretical basis for the conservation and management of carbon and water cycles in the functional areas of North China's ecosystems.
\end{abstract}

Keywords: WUE; spatiotemporal change; driving factors; ecosystem functional area; climate change

\section{Introduction}

In terrestrial ecosystems, vegetation cover plays an important role in energy and material balance through photosynthesis processes [1]. During photosynthesis, vegetation cover absorbs incident solar light and stores it as organic matter [2]. Furthermore, by producing oxygen and absorbing carbon dioxide, vegetation cover can adjust local, regional and global climate [3]. During these processes, the most important is primary production involving water consumption, carbon dioxide absorption, and organic matter production [4]. The primary productions of different vegetation types consume different amounts of water, which is one of the major restrictions on vegetation growth [5]. Therefore, it is important to determine the water consumption of different ecosystems, especially in different ecological function zones. 
WUE can be defined as the ratio between GPP and evapotranspiration (ET) [6-8] and is very helpful for understanding the carbon and water cycles of terrestrial ecosystems. Early studies on WUE mainly focused on the leaf level through in situ measurements and were time and labor intensive $[9,10]$. The ecosystem water use efficiency based on in-situ eddy covariance measurements has been extensively investigated throughout the world [11-13]. As measurements have advanced, scales of WUE have been extended to farmland [14,15], grassland [7,16] and forest [6,17-20]. With the help of remote sensing technology, GPP and ET product data have provided abundant data sources for WUE research at the local [21,22], regional [21,23] and global scales [24,25]. For example, WUE in most areas of the sandstorm source area in Beijing and Tianjin increased [26], and during the period from 1982 to 2015, the WUE of more than three-quarters of China increased [21]. The northern hemisphere WUE will be affected by phenological changes [27], and climate seasonal changes affect global WUE changes [28]. Sun, et al. [29] discovered that there were negative correlations between precipitation and WUE from 1979 to 2012. In addition to precipitation and temperature, leaf area index, soil moisture, water vapor and human activities are also potential influencing factors affecting WUE [30]. As discovered by $\mathrm{Du}$, et al. [31], climate factors contribute to $84 \%$ of WUE variations, while human activities contribute $16 \%$.

WUE, as defined by the ratio of GPP and ET, will be influenced first by GPP. Vegetation cover GPP is influenced by vegetation species, environmental conditions and human activities [32]. Therefore, it is necessary to analyze WUE considering vegetation species and environmental conditions. Ecological zones are defined as ecoregions where the majority of species and environmental conditions are similar. Chen, et al. [33] discovered that within the northern farming-pastoral region, vegetation dynamics show great spatiotemporal diversities. Du, et al. [34] pointed out that vegetation dynamics and courses in different ecological zones were largely different. Therefore, it is necessary to deeply investigate the dynamics and potential factors for different ecological zones.

The North China Plain is located in the hinterland of China, with a developed economy and convenient transportation. It is an important grain producing area in China and plays an important role in maintaining national security. The North China Plain has experienced environmental problems of land degradation and desertification [35]. In order to alleviate the above environmental and ecological problems, ecological restoration projects have been implemented to increase the vegetation coverage, etc., which have changed the carbon and water exchange between the atmosphere and the surface, thus affecting the spatiotemporal changes in WUE [26]. However, the shortage of water resources in the North China Plain and the large-scale decline of the groundwater level are important reasons for restricting the sustainable development of agriculture in the North China Plain. Improving water use efficiency is an important strategy to alleviate the water crisis and achieve sustainable crop production. The analysis of sustainable water use and water use efficiency provides a scientific basis for the efficient use and sustainable management of water resources in the North China Plain. As mentioned above, this study selected different ecological zones in the North China Plain to study the spatial, temporal, and driving factors of WUE in different ecoregions in the North China Plain.

\section{Data and Methods}

\subsection{Data}

In this study, remotely sensed GPP and ET datasets developed by Global Land Surface Satellite (GLASS) were used with a resolution of $0.05^{\circ}$ [36,37]. Yuan, et al. [37] simulated the GPP dataset with high accuracy based on the revised light utilization efficiency model, and the coefficient of determination between the observed and estimated GPP values was $0.81\left(R^{2}=0.81\right)$. Yao, et al. [36] combined five process-based algorithms using Bayesian model averaging to improve satellite-based global terrestrial LE estimates by comparing monthly LE observations at 240 sites with the algorithm's LE estimates. The algorithm has lower root mean square error $\left(32.8 \mathrm{~W} / \mathrm{m}^{2}\right)$ and R-squared value $(0.80)$. The verification of 
ground station data and estimated data shows the reliability of the GPP and ET remote sensing product data used in this paper. To analyze meteorological effects on WUE, the spatial resolution of temperature and precipitation data is $0.5^{\prime}$ [38]. The reclassified land use data (MCD12C1) in the study area are shown in Figure 1. In this study, ecosystem WUE is analyzed and non-vegetation areas are excluded.

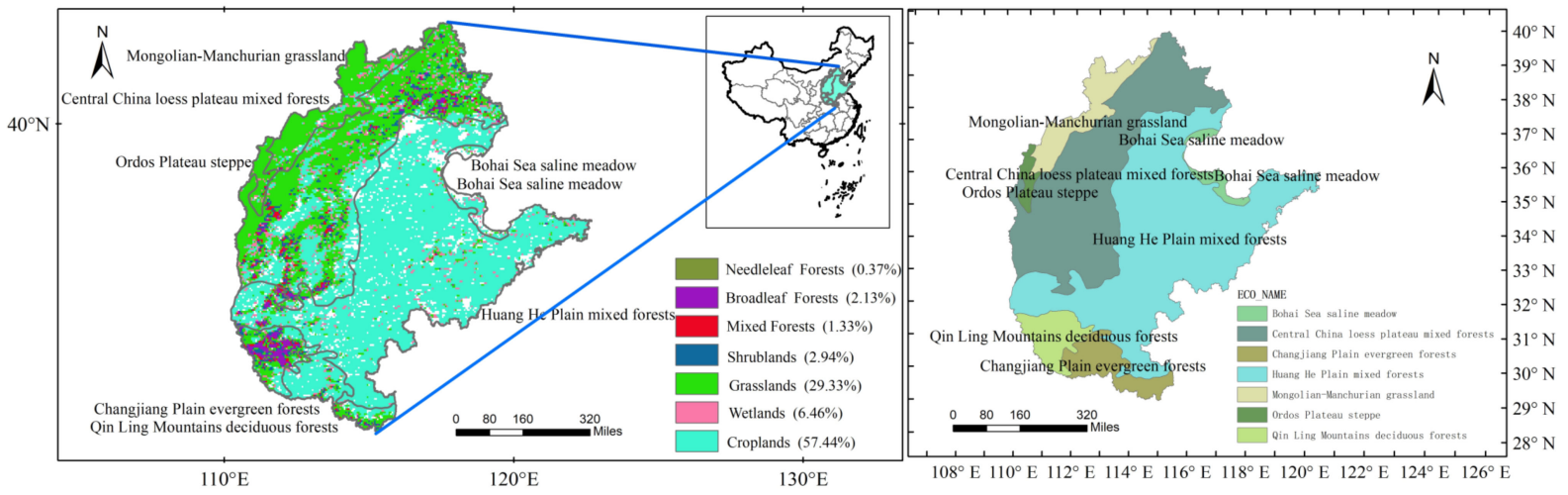

Figure 1. Spatial pattern of land use and ecosystem zoning locations in North China.

\subsection{Study Area}

The study area of this paper is the North China Plain, which mainly includes Henan Province, Hebei Province, Shanxi Province, Shandong Province, Beijing City and Tianjin City. In most areas of the North China Plain, the average temperature in July is $26-28^{\circ} \mathrm{C}$, and there is a lot of precipitation; in January, the average temperature is $-5 \sim 4{ }^{\circ} \mathrm{C}$, and the rainfall is less. Cultivated land and grassland vegetation types are mainly dominant in the study area, and they account for $57.44 \%$ and $29.33 \%$ of the total vegetation cover in the study area, respectively. The study area mainly includes the Bohai Sea saline meadow (BHSSM), Mongolian-Manchurian grassland (MGMG), Central China loess plateau mixed forests (CCLPMF), Ordos Plateau steppe (OPS), Huang He Plain mixed forests (HHPMF), Qin Ling Mountains deciduous forests (QLMDF), and Changjiang Plain evergreen forests (CJPEF) [39]. The spatial pattern of land use and ecosystem zoning locations in the North China Plain are shown in Figure 1.

\subsection{Methods}

\subsubsection{Technical Flowchart}

Based on the remote sensing products of GPP, ET and WUE in different ecosystem functional areas in the North China Plain, this paper investigates their spatial distribution and the main influence of GPP and ET on WUE. The change trend and stability of GPP, ET and WUE in different ecosystem functional areas were analyzed, and the spatial distributions of WUE driving factors were studied. The overall technical process is shown in Figure 2 .

\subsubsection{Water Use Efficiency}

The calculation formula of WUE is as follows:

$$
W U E=\frac{G P P}{E T}
$$

\subsubsection{Trend Analysis}

This study combined the Theil-Sen median trend and the Mann-Kendall test to analyze the long-term trend of WUE in the North China Plain. For convenience, this combination is called the Sen-MK method. First, the Theil-Sen Median trend is calculated as:

$$
\operatorname{Sen}=\operatorname{Median}\left(\frac{X_{k}-X_{l}}{k-l}\right), 2001 \leq l \leq k \leq 2017
$$


where Sen is the variation slope, and if Sen $>0$, it means that the sequence $X$ has an increasing trend, while Sen $<0$ suggests a decreasing trend. The Theil-Sen median trend provides no information about the significance of the sequence. Therefore, the MannKendall test was used to calculate the significance of the variation trend:

Let $\left\{X_{l}\right\}, l=2001,2002, \ldots, 2017$, the $Z$ value is:

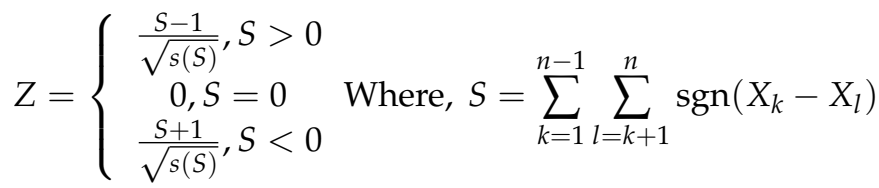

$$
\begin{aligned}
& \operatorname{sgn}\left(X_{k}-X_{l}\right)=\left\{\begin{array}{c}
1, X_{k}-X_{l}>0 \\
0, X_{k}-X_{l}=0 \\
-1, X_{k}-X_{l}<0
\end{array}, s(S)=\frac{n(n-1)(2 n+5)}{18}\right.
\end{aligned}
$$

When the absolute value of $\mathrm{Z}$ is greater than or equal to 1.96 , there is a significant change in WUE variation, on the contrary, the change in WUE variation is not significant.

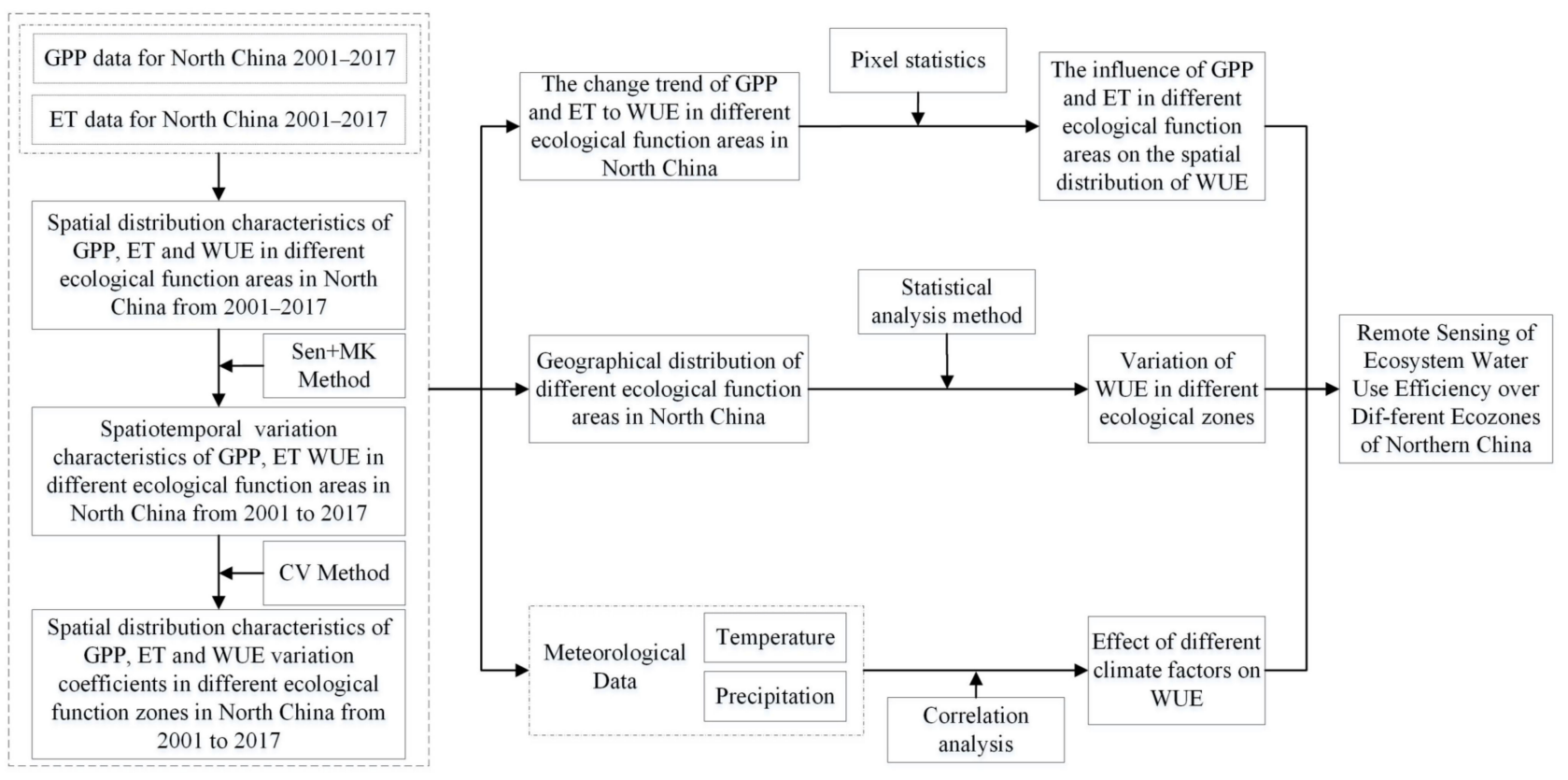

Figure 2. Overall technical flowchart.

\subsubsection{Correlation Analysis}

The Pearson correlation coefficient between WUE and climatic factors is calculated as follows:

$$
\operatorname{Cor}=\frac{\sum(m-\bar{m})(n-\bar{n})}{\sqrt{\sum(m-\bar{m})^{2} \sum(n-\bar{n})^{2}}}
$$

where Cor icoefficient, $\mathrm{m}$ is the climate factor sequence (precipitation and temperature), and $n$ is the ecosystem WUE sequence. The significance of WUE and climatic factors was tested using a t-test.

$$
\mathrm{t}=\frac{\operatorname{Cor} \sqrt{q-2}}{\sqrt{1-\operatorname{Cor}^{2}}}
$$

The $\mathrm{t}$-distribution of degrees of freedom $\mathrm{q}-2$ was followed, given a significance level $\alpha 1$ ( $p<0.05)$. If $t>t_{\alpha 1}$, the original hypothesis is not valid, and the correlation coefficient is considered significant. 


\subsubsection{Variation Coefficient}

The stability of WUE was quantified by using the variation coefficient (CV).

$$
C V_{W U E}=\frac{\sigma_{W U E}}{\overline{W U E}}
$$

where $C V_{W U E}$ represents the coefficient of variation of each pixel of WUE in North China from 2001 to 2017, $\sigma_{W U E}$ is the standard deviation of WUE values, and $\overline{W U E}$ is the multiyear mean of WUE in North China from 2001 to 2017. The smaller $C V_{W U E}$ is, the more stable the time series is, and vice versa, the more fluctuation there is. In this study, fluctuation will be divided into five classes: high fluctuation $\left(C V_{W U E}>0.5\right)$, moderate-high fluctuation $\left(0.15<C V_{W U E}<0.5\right)$, medium fluctuation $\left(0.1<C V_{W U E}<0.15\right)$, medium-low fluctuation $\left(0.05<C V_{W U E}<0.1\right)$, and low fluctuation $\left(C V_{W U E}<0.05\right)$.

\section{Results}

\subsection{WUE Spatial Variation}

The spatial distribution of multiyear averages of GPP, ET and WUE for seven ecoregions in the North China Plain from 2001 to 2017 is shown in Figure 3. The spatiotemporal distributions of GPP in the North China Plain had significant differences, and the high value areas of GPP (>1000 $\left.\mathrm{g} \mathrm{C} \mathrm{m}^{-2} \mathrm{y}^{-1}\right)$ are concentrated in the QLMDF, CJPEF and HHPMF ecological functional areas, while the low value areas of GPP $\left(<400 \mathrm{~g} \mathrm{C} \mathrm{m}^{-2} \mathrm{y}^{-1}\right)$ are concentrated in the MGMG, BHSSM and HHPMF ecological functional areas (Figure 3a). The spatiotemporal distribution of ET in the North China Plain has a clear distribution trend, gradually increasing from northwest to southeast, and the high ET values $\left(>800 \mathrm{~g} \mathrm{C} \mathrm{m}^{-2} \mathrm{y}^{-1}\right)$ are concentrated in the QLMDF, CJPEF and HHPMF ecological functional areas, while the low ET values are mainly distributed in the MGMG, CCLPMF and HHPMF ecological functional areas (Figure 3b). The spatiotemporal distributions of WUE and GPP in the North China Plain are similar, indicating that the spatial variation of WUE may be caused by GPP. The mean value of WUE in the North China Plain was $0.74 \mathrm{~g} \mathrm{C} \mathrm{m}^{-2} \mathrm{y}^{-1}$ (Figure 3c).

Figure 4 shows that the regions with increasing trends of GPP are concentrated in the northwestern and central-eastern parts of the North China Plain, while the regions with increasing trends of ET are concentrated in the western, southern, and eastern parts of the North China Plain, and the differences in the distribution of change trends of GPP and ET are relatively large. Compared with the spatial trend distribution of ET, the spatial trend distributions of WUE and GPP were more similar. In the study area, the WUE change trend was mainly influenced by the GPP change trend, which accounts for approximately $44.38 \%$ of the total study area. This is followed by the fact that the WUE variation trend was influenced by both GPP and ET variation trends, whose area accounts for approximately $19.75 \%$ of the area of the North China Plain. The influence of ET on the trend of WUE accounted for approximately $0.87 \%$ of the area of the North China Plain, indicating that GPP dominated the trend of WUE in the study area.

\subsection{WUE Temporal Variation}

The spatial distribution of change trends in GPP, ET and WUE in the North China Plain are shown in Figure 5. It can be observed that the significantly increased GPP areas in North China are concentrated in the northwestern and eastern parts of the North China Plain, and are distributed in the MGMG, CCLPMF and HHPMF ecological function areas. The area with increased GPP accounted for $66.05 \%$ of the area of the North China Plain, and the area with a significant increase $(p<0.05)$ in GPP accounted for $21.24 \%$ of the area of the North China Plain. The significantly increased ET was concentrated in the western, southern and eastern parts of the North China Plain, and distributed in the CCLPMF, CJPEF and HHPMF ecological function zones. The area with increased ET accounted for $66.23 \%$ of the area of the North China Plain, and the area with a significant increase $(p<0.05)$ in ET accounted for $28.30 \%$ of the area of the North China Plain. The trend of WUE mainly showed a mild decrease and a mild increase, accounting for $73.22 \%$ of the area of the North 
China Plain. In approximately the past decade, the change trend of WUE in the North China Plain has had a clear dividing line. The north of the central part has mainly shown an upward trend, and the south of the central part has mainly shown a downward trend. The area where WUE increased accounted for $58.65 \%$ of the area of the North China Plain, among which the area where WUE increased significantly $(p<0.05)$ accounted for $20.41 \%$ of the area of the North China Plain. The different trends in WUE in different regions of China indicate that the factors leading to changes in WUE are spatially complex.

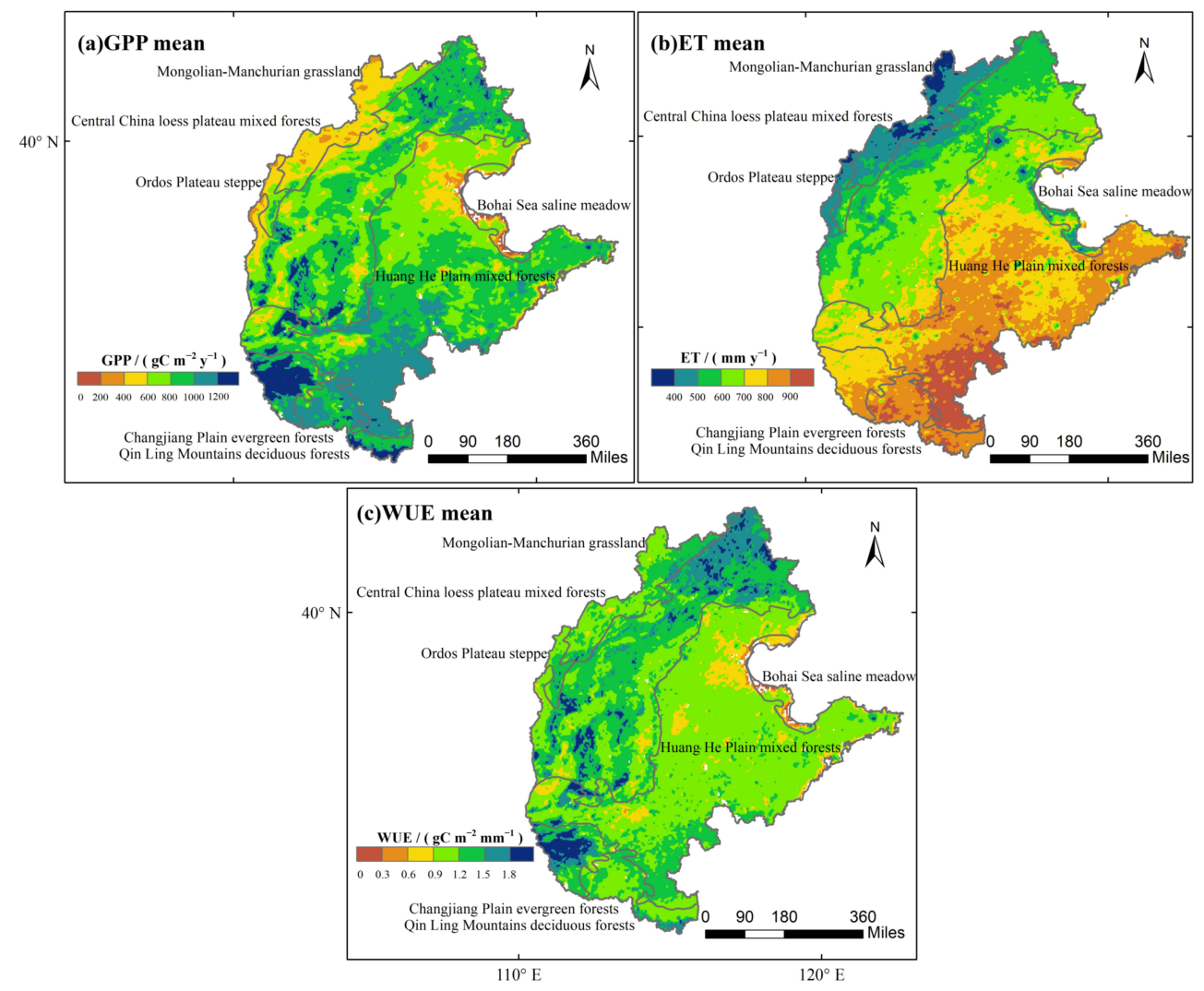

Figure 3. The spatial distribution of multiyear averages of GPP, ET and WUE for seven ecoregions in the North China Plain.

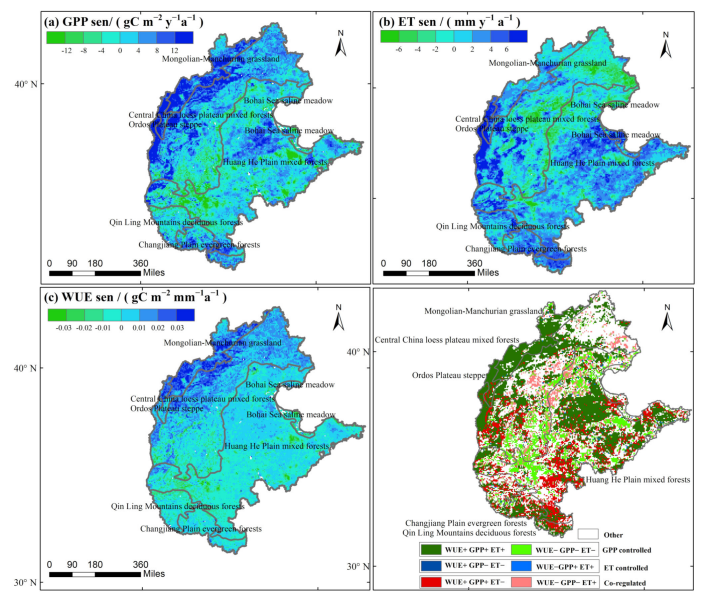

Figure 4. Influence of GPP and ET on the spatial distribution of WUE in different ecological functional areas (in Figure 6d, the symbol "+" indicates the increasing trend of annual WUE (GPP or ET), the symbol "-" indicates the decreasing trend of annual WUE (GPP or ET), and the blank indicates the uncertainty of annual WUE (GPP or ET)). 


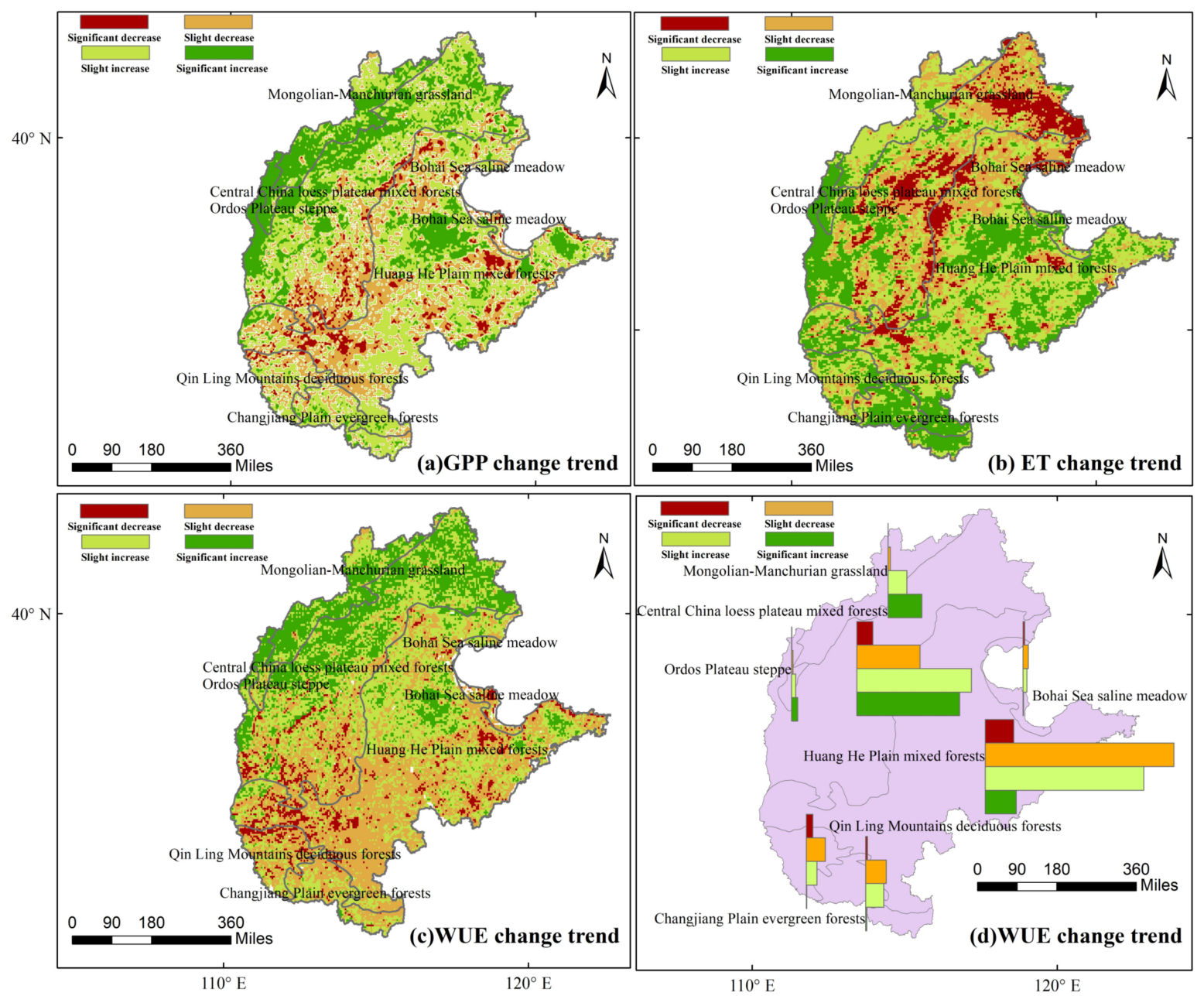

Figure 5. Spatial distribution of the trends of GPP, ET and WUE in the North China Plain.

The spatial distribution of the stability of GPP, ET and WUE in the North China Plain from 2001 to 2017 is shown in Figure 6. The GPP, ET and WUE in the North China Plain are relatively stable. Within the study area, the areas with medium-low fluctuations in GPP and WUE accounted for the largest proportion at $54.22 \%$ and $59.90 \%$ of the area of the North China Plain, respectively, and they were concentrated in the CCLPMF and HHPMF ecosystem functional areas. The areas with high fluctuations in GPP and WUE accounted for the smallest proportion, at $0.83 \%$ and $0.66 \%$ of the total study area, respectively, and were sporadically distributed in the study area. The spatial distribution and statistical results of WUE stability were similar to GPP. The area with small ET fluctuation accounts for $63.87 \%$ of the area of the North China Plain, and is mainly distributed in the QLMDF, CCLPMF, CJPEF and HHPMF ecosystem functional areas. Furthermore, there were no image elements with large fluctuations.

Different ecosystem types produce units of organic matter by consuming different amounts of water, which affects the spatiotemporal variation in WUE in different ecosystems. Therefore, it is important to study the characteristics of the WUE of different ecosystem types, as shown in Figure 7. The multiyear average values of WUE in the ecological function areas in North China were QLMDF > CCLPMF > MGMG > OPS > CJPEF > HHPMF > BHSSM in descending order, among which the multiyear mean values of WUE in the MGMG, OPS and CJPEF ecological function areas were not significantly different from each other. From 2001 to 2017, the WUE of the MGMG, CCLPMF and OPS ecosystems showed a growing trend, among which the WUE of the MGMG ecological function area grew the fastest, which might be related to the construction of the "Three Norths" protection forest project. However, the other four ecological 
functional areas showed a decreasing trend, and the WUE of the QLMDF ecological functional area decreased at the fastest rate.
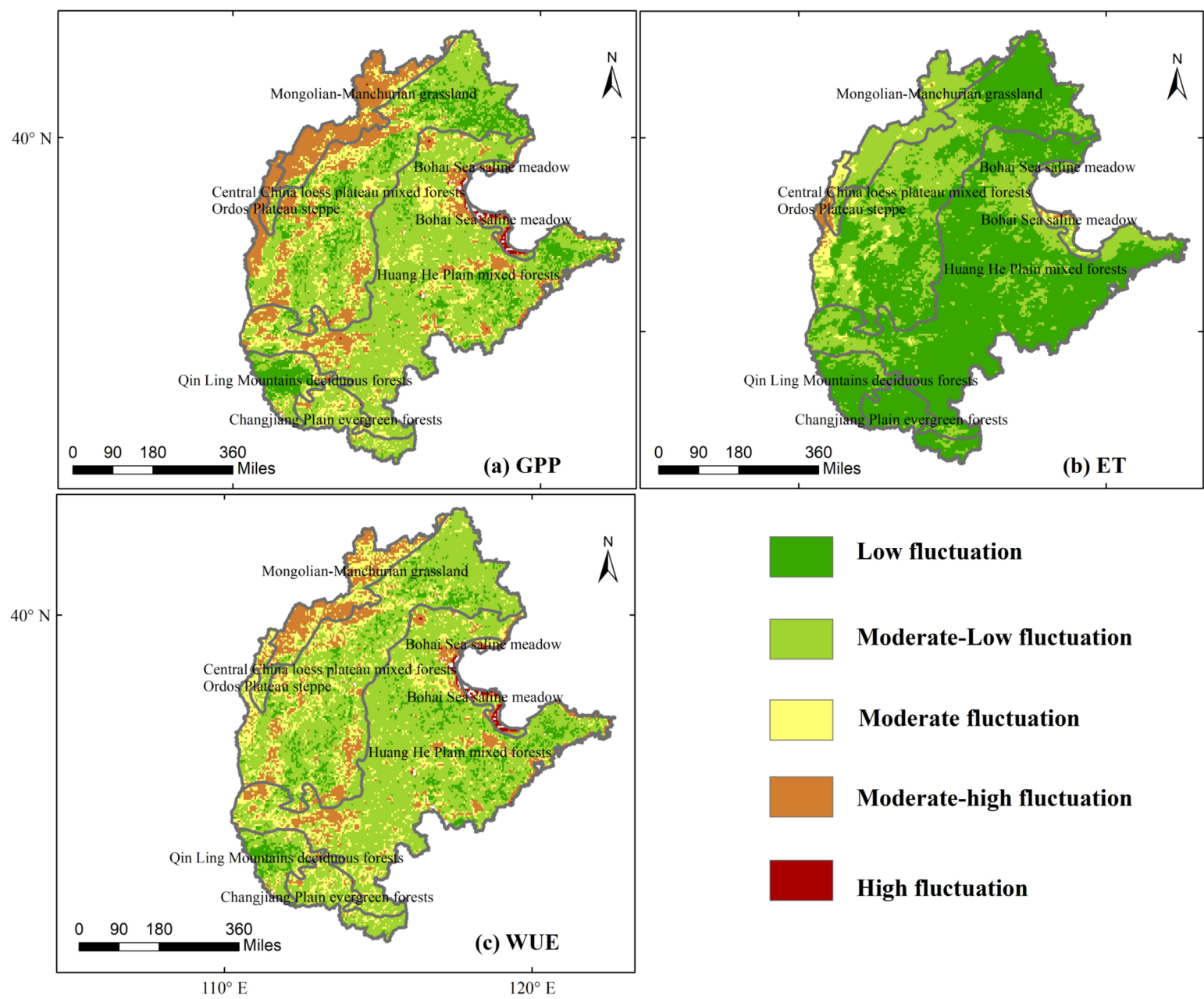

Low fluctuation

Moderate-Low fluctuation

Moderate fluctuation

Moderate-high fluctuation

High fluctuation

Figure 6. Spatial distribution of GPP, ET and WUE stability in the North China Plain.

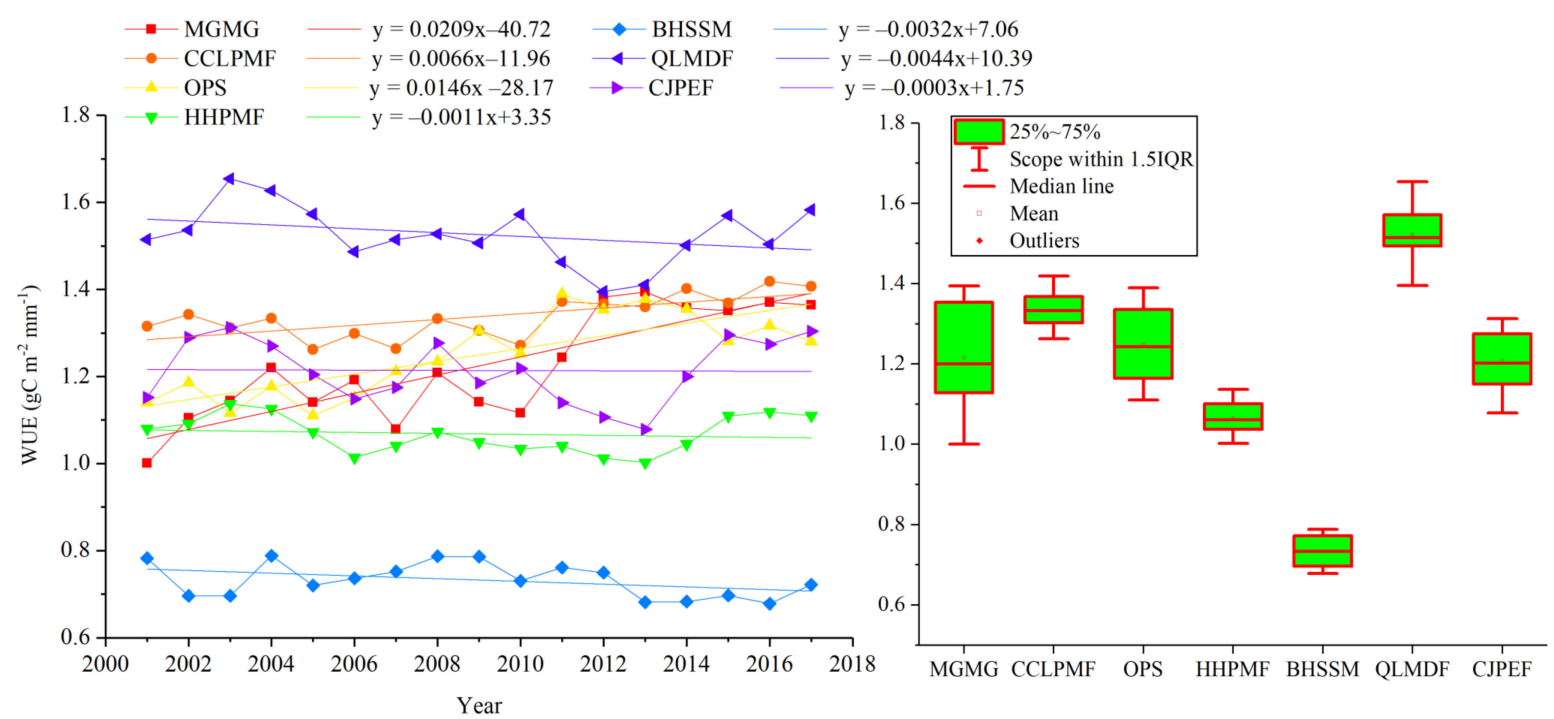

Figure 7. Trend and box plot of WUE in different ecological function areas. 


\subsection{Influence of Different Climatic Factors}

Figure 8 shows the spatial correlations of WUE with precipitation and temperature. The change of WUE in most areas of the North China Plain has little relationship with temperature (the area with slight correlation is $85.27 \%$ ), and only a small part of the change of WUE is affected by temperature (14.73\%), and scattered in the North China Plain. Among them, the area of WUE that increases with temperature is only $3.42 \%$. The area of WUE that increases with the increase of precipitation accounts for $23.74 \%$ of the area of the North China Plain, and is mainly distributed in the QLMDF, CJPEF and HHPMF ecological functional areas. Similar to temperature, the change of WUE in most areas of the North China Plain has little relationship with precipitation (the area with slight correlation is $76.03 \%$ ).

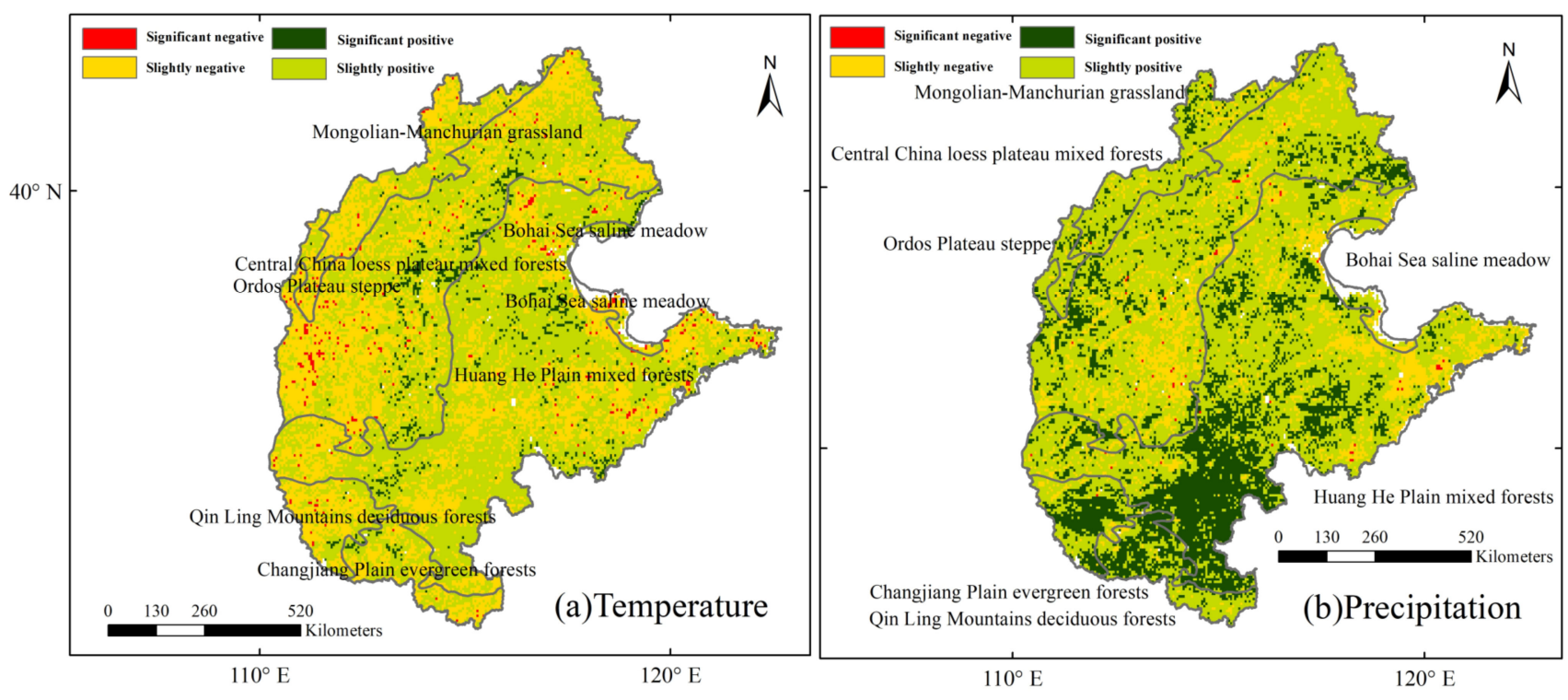

Figure 8. Spatial correlation of WUE with precipitation and temperature.

\section{Discussion}

\subsection{WUE Spatial Variation and Driving Factors}

The ecological restoration projects implemented in North China have an impact on the ecosystem carbon and water cycle [40]. The annual variation of WUE in the Beijing-Tianjin sand source region ranges from 0.03 to $4.10 \mathrm{~g} \mathrm{C} \mathrm{m}^{-2} \mathrm{y}^{-1}$ [26], similar to the results of this paper. In 2001-2017, the area showing an increasing trend in WUE accounted for $58.65 \%$ of the area of the North China Plain, and the findings were consistent with those of Guo, et al. [21]. These findings may be related to ecological restoration (e.g., reforestation and desertification management) causing land use/land cover changes, leading to an increase in vegetation greenness and thus affecting changes in carbon and water cycles [41]. Because most species and environmental conditions are similar within an ecological zone, there is little variation in the spatiotemporal distribution of WUE for an ecological functional area. The WUE of different ecological functional areas is closely related to the distribution of vegetation in the North China Plain; for example, the highest mean value of WUE in the QLMDF ecosystem functional area may be related to the high distribution of forest in this ecosystem functional area. The trend of WUE changes in the North China Plain was mainly influenced by the trend of GPP changes, which accounted for approximately $44.38 \%$ of the total study area. This may be related to the related engineering of vegetation restoration. Compared with bare land, the increase of vegetation cover increases both GPP and ET. However, the greater increase in GPP than ET is the main reason for the increase in WUE [8]. 
Different driving factors have different effects on the spatiotemporal variation of WUE in different study areas [31]. There are many factors that affect the variation of WUE, such as vegetation type and climatic factors. Land cover change has large effects on physicobiogeochemical processes that can alter WUE [42,43], indicating that different land cover WUE has some differences $[21,44]$. Vegetation types and environmental conditions are very similar in the same ecosystem functional area, but vegetation types and environmental conditions are very different in different ecosystem functional areas, so there are great differences in WUE in different ecosystem functional areas, i.e., ecosystem functional areas with high cover vegetation types have higher WUE values.

The influence of climatic factors on the WUE of terrestrial ecosystems is extremely important, and temperature and precipitation determine the basic structure and distribution of climate and vegetation. From the analysis of the driving factors of the spatiotemporal variation of WUE, the response of precipitation to WUE in the North China Plain is greater than that of temperature, which is consistent with the research results of Gang et al. [16]. In addition, WUE is positively correlated with precipitation in most areas of the BeijingTianjin sand source [26], and in the Loess Plateau, WUE and precipitation are also positively correlated $[45,46]$. However, in some grasslands, excessive precipitation also has a negative spatial effect on WUE. In addition, WUE at flow stations in China all show a positive sensitivity to temperature [47]. In addition, in the Loess Plateau and the Beijing-Tianjin sand source region, the area where WUE is positively correlated with temperature accounts for most of the area $[26,45]$. It shows that WUE in the ecosystem of northern China may decrease with warming and increase with the increase of precipitation, but the degree of change may vary according to vegetation type and water conditions [26]. Furthermore, humidity rather than temperature is the main control factor of regional WUE, which is also consistent with the above view [48]. The above results on the spatial distribution of the correlation between WUE and climatic conditions are consistent with the results in Figure 8 in this paper.

\subsection{Limitation and Future Perspectives}

This paper has studied the spatiotemporal variation of WUE and its driving factors in different ecological functional areas in North China from 2001 to 2017, with a very comprehensive analysis of the variations and driving factors of WUE in different ecological functional areas in North China, but there are still some shortcomings. On the one hand, because the remote sensing inversion data products and meteorological data used in this paper may have some errors themselves, these differences may lead to some errors in the analysis results. On the other hand, two climate factors (precipitation and temperature) were selected in this study to analyze the correlation between WUE and impact factors, and other impact factors were not added to the WUE driving factor analysis. Finally, the WUE data obtained from GPP and ET remote sensing data are not verified with the ground real-time monitoring data, so there are many uncertainties. Therefore, in future studies, remote sensing products and climate data with higher accuracy inversion are needed to more comprehensive analyze the influence of other factors affecting WUE changes in the study area and to analyze the likelihood that WUE is influenced by external influencing factors in multiple ways. Moreover, the accuracy of WUE remote sensing data needs to be verified by ground data.

\section{Conclusions}

Based on remote sensing data products, this paper studies the spatiotemporal variation of WUE and its driving factors in different ecological functional areas in the North China Plain from 2001 to 2017. The spatial distribution of WUE and GPP in the North China Plain is similar, with the multiyear average of WUE at $0.74 \mathrm{~g} \mathrm{C} \mathrm{m}^{-2} \mathrm{y}^{-1}$. The variation trend of WUE is mainly affected by the variation trend of GPP, and its area accounts for about $44.38 \%$ of the total area of the study area. The change trend of WUE mainly showed a mild decrease and a mild increase, accounting for $73.22 \%$ of the total area of the study area; the area 
with medium-low fluctuation of WUE accounted for the largest proportion, accounting for $59.90 \%$ of the total area of the study area. In addition, the multiyear average value of WUE in the ecological functional area is Qin Ling Mountains deciduous forests $>$ Central China loess plateau mixed forests $>$ Mongolian-Manchurian grassland $>$ Ordos Plateau steppe $>$ Changjiang Plain evergreen forests $>$ Huang He Plain mixed forests $>$ Bohai Sea saline meadow, from high to low. The influence of precipitation on WUE is higher than that of temperature. The area of WUE that increased with the increase of precipitation accounted for $23.74 \%$ of the area of the North China Plain, and was mainly distributed in the QLMDF, CJPEF and HHPMF ecological functional areas. The above analysis of WUE changes and their driving factors in the ecosystem functional areas of the North China Plain further allows us to understand the WUE changes and their driving factors in different ecosystem functional areas and provides a reference and theoretical basis for better protection and restoration of the carbon and water cycles in ecosystem functional areas.

Author Contributions: Conceptualization, methodology, writing, Y.H.; software, W.C.; investigation, G.L. All authors have read and agreed to the published version of the manuscript.

Funding: This research was funded by the National Natural Science Foundation of China (NSFC) (grant number 41930650) and the National Key Research and Development Program of China (grant number 2016YFB0501404).

Institutional Review Board Statement: Not applicable.

Informed Consent Statement: Not applicable.

Data Availability Statement: Data sharing not applicable.

Conflicts of Interest: The authors declare no conflict of interest.

\section{References}

1. Jin, Z.; Liang, W.; Yang, Y.; Zhang, W.; Yan, J.; Chen, X.; Li, S.; Mo, X. Separating Vegetation Greening and Climate Change Controls on Evapotranspiration trend over the Loess Plateau. Sci. Rep. 2017, 7, 8191. [CrossRef] [PubMed]

2. Ge, J.; Guo, W.; Pitman, A.J.; De Kauwe, M.G.; Chen, X.; Fu, C. The Nonradiative Effect Dominates Local Surface Temperature Change Caused by Afforestation in China. J. Clim. 2019, 32, 4445-4471. [CrossRef]

3. Delgado, R.C.; Pereira, M.G.; Teodoro, P.E.; dos Santos, G.L.; de Carvalho, D.C.; Magistrali, I.C.; Vilanova, R.S. Seasonality of gross primary production in the Atlantic Forest of Brazil. Glob. Ecol. Conserv. 2018, 14, e00392. [CrossRef]

4. Chen, C.; Park, T.; Wang, X.; Piao, S.; Xu, B.; Chaturvedi, R.K.; Fuchs, R.; Brovkin, V.; Ciais, P.; Fensholt, R.; et al. China and India lead in greening of the world through land-use management. Nat. Sustain. 2019, 2, 122-129. [CrossRef]

5. Li, Y.; Wang, X.; Chen, Y.; Wang, M. Land surface temperature variations and their relationship to fractional vegetation coverage in subtropical regions: A case study in Fujian Province, China. Int. J. Remote Sens. 2019, 41, 2081-2097. [CrossRef]

6. Song, Q.H.; Fei, X.H.; Zhang, Y.P.; Sha, L.Q.; Liu, Y.T.; Zhou, W.J.; Wu, C.S.; Lu, Z.Y.; Luo, K.; Gao, J.B.; et al. Water use efficiency in a primary subtropical evergreen forest in Southwest China. Sci. Rep. 2017, 7, 43031. [CrossRef]

7. Wang, Y.; Ma, Y.; Li, H.; Yuan, L. Carbon and water fluxes and their coupling in an alpine meadow ecosystem on the northeastern Tibetan Plateau. Theor. Appl. Climatol. 2020, 142, 1-18. [CrossRef]

8. Yang, Y.; Guan, H.; Batelaan, O.; McVicar, T.R.; Long, D.; Piao, S.; Liang, W.; Liu, B.; Jin, Z.; Simmons, C.T. Contrasting responses of water use efficiency to drought across global terrestrial ecosystems. Sci. Rep. 2016, 6, 23284. [CrossRef]

9. Martin, B.; Thorstenson, Y.R. Stable Carbon Isotope Composition (delta-c-13), Water Use Efficiency, and Biomass Productivity of Lycopersicon esculentum, Lycopersicon pennellii, and the F1 Hybrid. Plant Physiol. 1988, 88, 213-217. [CrossRef]

10. Donovan, L.A.; Dudley, S.A.; Rosenthal, D.M.; Ludwig, F. Phenotypic selection on leaf water use efficiency and related ecophysiological traits for natural populations of desert sunflowers. Oecologia 2007, 152, 13-25. [CrossRef]

11. Yu, G.; Song, X.; Wang, Q.; Liu, Y.; Guan, D.; Yan, J.; Sun, X.; Zhang, L.; Wen, X. Water-use efficiency of forest ecosystems in eastern China and its relations to climatic variables. New Phytol. 2008, 177, 927-937. [CrossRef] [PubMed]

12. Zhu, X.; Yu, G.; Wang, Q.; Hu, Z.; Han, S.; Yan, J.; Wang, Y.; Zhao, L. Seasonal dynamics of water use efficiency of typical forest and grassland ecosystems in China. J. For. Res. 2014, 19, 70-76. [CrossRef]

13. Zhu, X.-J.; Yu, G.-R.; Wang, Q.-F.; Hu, Z.-M.; Zheng, H.; Li, S.-G.; Sun, X.-M.; Zhang, Y.-P.; Yan, J.-H.; Wang, H.-M.; et al. Spatial variability of water use efficiency in China's terrestrial ecosystems. Glob. Planet. Chang. 2015, 129, 37-44. [CrossRef]

14. Wang, H.; Li, X.; Tan, J. Interannual Variations of Evapotranspiration and Water Use Efficiency over an Oasis Cropland in Arid Regions of North-Western China. Water 2020, 12, 1239. [CrossRef]

15. Wang, Y.; Zhou, L.; Ping, X.; Jia, Q.; Li, R. Ten-year variability and environmental controls of ecosystem water use efficiency in a rainfed maize cropland in Northeast China. Field Crop. Res. 2018, 226, 48-55. [CrossRef] 
16. Gang, C.; Wang, Z.; Zhou, W.; Chen, Y.; Li, J.; Chen, J.; Qi, J.; Odeh, I.; Groisman, P.Y. Assessing the Spatiotemporal Dynamic of Global Grassland Water Use Efficiency in Response to Climate Change from 2000 to 2013. J. Agron. Crop Sci. 2016, 202, 343-354. [CrossRef]

17. Jiang, Y.; Still, C.J.; Rastogi, B.; Page, G.F.M.; Wharton, S.; Meinzer, F.C.; Voelker, S.; Kim, J.B. Trends and controls on water-use efficiency of an old-growth coniferous forest in the Pacific Northwest. Environ. Res. Lett. 2019, 14, 074029. [CrossRef]

18. Liu, X.; Chen, X.; Li, R.; Long, F.; Zhang, L.; Zhang, Q.; Li, J. Water-use efficiency of an old-growth forest in lower subtropical China. Sci. Rep. 2017, 7, 42761. [CrossRef]

19. Tang, X.; Li, H.; Xu, X.; Luo, J.; Li, X.; Ding, Z.; Xie, J. Potential of MODIS data to track the variability in ecosystem water-use efficiency of temperate deciduous forests. Ecol. Eng. 2016, 91, 381-391. [CrossRef]

20. Xie, J.; Chen, J.; Sun, G.; Zha, T.; Yang, B.; Chu, H.; Liu, J.; Wan, S.; Zhou, C.; Ma, H.; et al. Ten-year variability in ecosystem water use efficiency in an oak-dominated temperate forest under a warming climate. Agric. For. Meteorol. 2016, 218, 209-217. [CrossRef]

21. Guo, L.; Sun, F.; Liu, W.; Zhang, Y.; Wang, H.; Cui, H.; Wang, H.; Zhang, J.; Du, B. Response of Ecosystem Water Use Efficiency to Drought over China during 1982-2015: Spatiotemporal Variability and Resilience. Forests 2019, 10, 598. [CrossRef]

22. Tang, X.; Ma, M.; Ding, Z.; Xu, X.; Yao, L.; Huang, X.; Gu, Q.; Song, L. Remotely Monitoring Ecosystem Water Use Efficiency of Grassland and Cropland in China's Arid and Semi-Arid Regions with MODIS Data. Remote Sens. 2017, 9, 616. [CrossRef]

23. Zhao, A.; Zhang, A.; Cao, S.; Feng, L.; Pei, T. Spatiotemporal patterns of water use efficiency in China and responses to multi-scale drought. Theor. Appl. Climatol. 2020, 140, 559-570. [CrossRef]

24. Liu, X.; Feng, X.; Fu, B. Changes in global terrestrial ecosystem water use efficiency are closely related to soil moisture. Sci. Total Environ. 2020, 698, 134165. [CrossRef]

25. Lu, X.; Chen, M.; Liu, Y.; Miralles, D.G.; Wang, F. Enhanced water use efficiency in global terrestrial ecosystems under increasing aerosol loadings. Agric. For. Meteorol. 2017, 237, 39-49. [CrossRef]

26. Guo, L.; Shan, N.; Zhang, Y.; Sun, F.; Liu, W.; Shi, Z.; Zhang, Q. Separating the effects of climate change and human activity on water use efficiency over the Beijing-Tianjin Sand Source Region of China. Sci. Total Environ. 2019, 690, 584-595. [CrossRef] [PubMed]

27. Jin, J.; Wang, Y.; Zhang, Z.; Magliulo, V.; Jiang, H.; Cheng, M. Phenology Plays an Important Role in the Regulation of Terrestrial Ecosystem Water-Use Efficiency in the Northern Hemisphere. Remote Sens. 2017, 9, 664. [CrossRef]

28. Huang, M.; Piao, S.; Zeng, Z.; Peng, S.; Ciais, P.; Cheng, L.; Mao, J.; Poulter, B.; Shi, X.; Yao, Y.; et al. Seasonal responses of terrestrial ecosystem water-use efficiency to climate change. Glob. Chang. Biol. 2016, 22, 2165-2177. [CrossRef]

29. Sun, S.; Song, Z.; Wu, X.; Wang, T.; Wu, Y.; Du, W.; Che, T.; Huang, C.; Zhang, X.; Ping, B.; et al. Spatio-temporal variations in water use efficiency and its drivers in China over the last three decades. Ecol. Indic. 2018, 94, 292-304. [CrossRef]

30. Lu, Y.; Zhang, X.; Chen, S.; Shao, L.; Sun, H. Changes in water use efficiency and water footprint in grain production over the past 35 years: A case study in the North China Plain. J. Clean. Prod. 2016, 116, 71-79. [CrossRef]

31. Du, X.; Zhao, X.; Zhou, T.; Jiang, B.; Xu, P.; Wu, D.; Tang, B. Effects of Climate Factors and Human Activities on the Ecosystem Water Use Efficiency throughout Northern China. Remote Sens. 2019, 11, 2766. [CrossRef]

32. Li, G.C.; Chen, W.; Li, R.R.; Zhang, X.P.; Liu, J.L. Assessing the spatiotemporal dynamics of ecosystem water use efficiency across China and the response to natural and human activities. Ecol. Indic. 2021, 126, 107680. [CrossRef]

33. Chen, W.; Li, A.; Hu, Y.; Li, L.; Zhao, H.; Han, X.; Yang, B. Exploring the long-term vegetation dynamics of different ecological zones in the farming-pastoral ecotone in northern China. Environ. Sci. Pollut. R 2021, 28, 27914-27932. [CrossRef] [PubMed]

34. Du, J.Q.; Fang, S.F.; Sheng, Z.L.; Wu, J.H.; Quan, Z.J.; Fu, Q. Variations in vegetation dynamics and its cause in national key ecological function zones in China. Environ. Sci. Pollut. R 2020, 27, 30145-30161. [CrossRef]

35. Huang, S.W.; Kong, J.M. Assessing Land Degradation Dynamics and Distinguishing Human-Induced Changes from Climate Factors in the Three-North Shelter Forest Region of China. ISPRS Int. J. Geo-Inf. 2016, 5, 158. [CrossRef]

36. Yao, Y.; Liang, S.; Li, X.; Hong, Y.; Fisher, J.B.; Zhang, N.; Chen, J.; Cheng, J.; Zhao, S.; Zhang, X.; et al. Bayesian multimodel estimation of global terrestrial latent heat flux from eddy covariance, meteorological, and satellite observations. J. Geophys. Res. Atmos. 2014, 119, 4521-4545. [CrossRef]

37. Yuan, W.P.; Liu, S.G.; Yu, G.R.; Bonnefond, J.M.; Chen, J.Q.; Davis, K.; Desai, A.R.; Goldstein, A.H.; Gianelle, D.; Rossi, F.; et al. Global estimates of evapotranspiration and gross primary production based on MODIS and global meteorology data. Remote Sens. Environ. 2010, 114, 1416-1431. [CrossRef]

38. Peng, S.; Ding, Y.; Liu, W.; Li, Z. 1 km monthly temperature and precipitation dataset for China from 1901 to 2017. Earth Syst. Sci. Data 2019, 11, 1931-1946. [CrossRef]

39. Turner, W.R.; Brandon, K.; Brooks, T.M.; Costanza, R.; da Fonseca, G.A.B.; Portela, R. Global conservation of biodiversity and ecosystem services. Bioscience 2007, 57, 868-873. [CrossRef]

40. Liu, D.; Chen, Y.; Cai, W.; Dong, W.; Xiao, J.; Chen, J.; Zhang, H.; Xia, J.; Yuan, W. The contribution of China's Grain to Green Program to carbon sequestration. Landsc. Ecol. 2014, 29, 1675-1688. [CrossRef]

41. Zhou, S.; Yu, B.; Schwalm, C.R.; Ciais, P.; Zhang, Y.; Fisher, J.B.; Michalak, A.M.; Wang, W.; Poulter, B.; Huntzinger, D.N.; et al. Response of Water Use Efficiency to Global Environmental Change Based on Output From Terrestrial Biosphere Models. Glob. Biogeochem. Cycles 2017, 31, 1639-1655. [CrossRef] 
42. Jarosz, N.; Béziat, P.; Bonnefond, J.M.; Brunet, Y.; Calvet, J.C.; Ceschia, E.; Elbers, J.A.; Hutjes, R.W.A.; Traullé, O. Effect of land use on carbon dioxide, water vapour and energy exchange over terrestrial ecosystems in Southwestern France during the CERES campaign. Biogeosci. Discuss. 2009, 6, 2755-2784.

43. Sakai, R.K.; Fitzjarrald, D.R.; Moraes, O.L.L.; Staebler, R.M.; Acevedo, O.C.; Czikowsky, M.J.; Da Silva, R.; Brait, E.; Miranda, V. Land-use change effects on local energy, water, and carbon balances in an Amazonian agricultural field. Glob. Chang. Biol. 2004, 10, 895-907. [CrossRef]

44. Zhao, J.; Xu, T.; Xiao, J.; Liu, S.; Mao, K.; Song, L.; Yao, Y.; He, X.; Feng, H. Responses of Water Use Efficiency to Drought in Southwest China. Remote Sens. 2020, 12, 199. [CrossRef]

45. Wang, L.; Li, M.; Wang, J.; Li, X.; Wang, L. An analytical reductionist framework to separate the effects of climate change and human activities on variation in water use efficiency. Sci. Total Environ. 2020, 727, 138306. [CrossRef]

46. Zheng, H.; Lin, H.; Zhu, X.-J.; Jin, Z.; Bao, H. Divergent spatial responses of plant and ecosystem water-use efficiency to climate and vegetation gradients in the Chinese Loess Plateau. Glob. Planet. Chang. 2019, 181, 102995. [CrossRef]

47. Li, Y.; Shi, H.; Zhou, L.; Eamus, D.; Huete, A.; Li, L.H.; Cleverly, J.; Hu, Z.M.; Harahap, M.; Yu, Q.; et al. Disentangling Climate and LAI Effects on Seasonal Variability in Water Use Efficiency Across Terrestrial Ecosystems in China. J. Geophys. Res. Biogeosci. 2018, 123, 2429-2443. [CrossRef]

48. Zhang, T.; Peng, J.; Liang, W.; Yang, Y.; Liu, Y. Spatial-temporal patterns of water use efficiency and climate controls in China's Loess Plateau during 2000-2010. Sci. Total Environ. 2016, 565, 105-122. [CrossRef] 